OPEN ACCESS

Edited by:

Fred Provenza,

Utah State University, United States

Reviewed by: Carol Margaret Stansfield Smith, Lincoln University, New Zealand Christopher Rosin,

Lincoln University, New Zealand

${ }^{*}$ Correspondence:

Christopher J. K. Perley

chris@thoughtscapes.co.nz

Specialty section

This article was submitted to Agroecology and Ecosystem Services, a section of the journal Frontiers in Sustainable Food Systems

Received: 17 April 2020

Accepted: 15 April 2021

Published: 06 August 2021

Citation:

Perley CJK (2021) Pastoral Agriculture in the Post-industrial Age: Building Functional Integrity and Realising doi: 10.3389/fsufs. 2021.552838

\section{Pastoral Agriculture in the Post-industrial Age: Building Functional Integrity and Realising Potential}

\author{
Christopher J. K. Perley* \\ Thoughtscapes, Hastings, New Zealand
}

The potential of pastoral land use to create positive environmental, economic, and social outcomes is constrained by a "way of seeing" land and people through the eyes of Modernity and mechanical determinism. That ontology of land is compounded and reinforced by positivism, and the associated hierarchical and dis-integrated epistemology around the culture:nature nexus - including what is seen as "objective" science and technology driving practise. Both the ontology and epistemology of our Modern land use culture drive a reduction of ethics, relationship, and meaning to the measured utility of either production or dollars within a "resource sufficiency" view of the land factory. The consequence is not just the non-realisation of potential synergies and multiple functions underpinning value and resilience within the socio-ecological systems associated with pastoral land. It also degrades the "functional integrity" of those integrated systems and increases the fragility and multiple negative outcomes to local economic, environmental, and social functions. This study examines the underlying philosophical thoughtscapes of Modern agri-business models and contrasts those models with the emerging alternatives: from reducible universally-quantifiable machines to post-industrial thought; including post-normal science, integrated complex adaptive systems, and emerging work shifting homogeneous "economies of scale" industrialism to realising potential "economies of scope" by building functional and self-organising systems. It further examines the potential scope to be gained using three specific examples: multi-functional integrated landscapes, resilience theory specific to drought, and market value chains.

Keywords: functional integrity, socio-ecological systems, agroecological systems, ontology of land, economies of scope, post-industrialism, agricultural industrialism

\section{CONCEPTUAL ANALYSIS: INTRODUCTION}

\begin{abstract}
"There are these two young fish swimming along, and they happen to meet an older fish swimming the other way who nods at them and says, "Morning, boys. How's the water?" And the two young fish swim on for a bit, and then, eventually, one of them looks over at the other and goes, "What the hell is water?"
\end{abstract}

David Foster Wallace "This Is Water: Some Thoughts, Delivered on a Significant Occasion, about Living a Compassionate Life" 
Landscapes are a contest of ideas. We "see" them through a cultural lens - from sinister to transcendent, as agronomic resources or pure cultureless nature, as utility or memory, and as "other" and outside ourselves; we also see them as integrated with their community and as interconnected systems, complex, uncertain, constantly in flux, constantly in contact with multiple domains. Such cultural "lenses" - whether called paradigms, worldviews, framings, or metaphors by which we see and live are built within us through upbringing, education, and through our own reflexive relationship with any particular piece of land (Glenna, 1996).

We are also influenced by the dominant power relationships and wider political ecologies within which research, policy, and practise reside. That is the wider context. However, the focus of this paper is on the ideas underpinning research, policy, and practise rather than a comprehensive examination of the wider political ecologies at both national and international levels, including those particular and growing shifts in power relationships as local 'grass roots' communities challenge the dominant framing and practises associated with land and community.

Landscapes are thoughtscapes, not objective spaces. We see what the constraints and scope of our cultural lens allows us to see. What we create reflects what Pierre Bourdieu defined as Habitus (Bourdieu, 1977): the customary, "pre-law" practises we see as right and wrong and good and bad, all associated with a personal culture within, which both limits and allows. Within one culture, someone will eat a dog without a thought. In another, they will not. "This is what we do."

What we make of a landscape, a farm, or its associated community, is a manifestation of Habitus. The landscape we make reflects back on us, usually in confirmation. It is not just the practise of people more intimate with land who see and create this way, it is the institutions of government (Scott, 1999), policy making, commerce, education, and research.

For those of us raised in the non-Humanities disciplines, in supposed "facts," such deeper questions are uncommon. We deal in the implicit analytical and "positive" traditions: in uncontested assumptions of objective measured things. We tend to measure what can fit within our methods, our assumptions of metaphysics and epistemology, and even by what is easily measured in time and place. The path of least resistance is studied. The less easy road, however more important, waits its turn.

This underlying sociology of research and practise is not the premise of any call to dismiss all actions as relative. It is a call to consider what lies beneath; particularly to first acknowledge and then question the Modern and positivist mechanical metaphysical ideas that currently underpin the questionable industrialism of land and community. From that acknowledgement, the questions of appropriateness and alternative naturally flow.

There are alternatives. Arguably one of the big three scientific shocks of the twentieth Century, alongside Einstein's Relativity and Heisenberg's Uncertainty Principle, was Complexity Theory (Gleich, 1987). The reductionist Newtonian world of universal rules does not relate well to all contexts.
People are obviously one of those contexts, where a Newtonian approach reduces humanity to a set of biophysical measures, destroying the essence of humanity, reducing potential and increasing the chance of dysfunction and failure. Extreme examples illustrate the point. Newtonian Behaviourist experiments in raising animals and children as machines - the post-Soviet Romanian orphanages: the live vivisection of what were presumed to be the animal "machine" of the seventeenth and eighteenth centuries - are examples of wrongly framing a Complex Adaptive System as simple machines; none of these can be objectified and reduced without the serious loss of something, including morality.

For land and their communities - socio-ecological systems the same questions require an answer. Can land and communities be reduced in such a way, without a significant loss of perspective, that is sufficient to lose not just a sense of right and wrong but also an awareness of the consequences of what we do?

A landscape and the ecosystems within are inherently multifunctional, interdependent, complex, and adaptive. Include culture within that nature, not just as framed by socio-ecological research, but also through the functions of economics, and that land is more complex still.

Newtonian regularity in such a context is an ontological fallacy; it is no more logical than reducing a child to a calorie input-output machine.

We lose potential and increase "unforeseen" problems when we look to our landscapes through the industrial lens of Modernity. We lose values, and opportunities by seeing the world so.

Many of those losses and gains relate to the potential "scope" of mutualisms and synergistic landscape functions - ecological, economic, and social - that the analytical single-disciplinary mind is trained not to see, and therefore either not realise, or to destroy.

\section{THE MACHINE AND THE SYSTEM}

Within land use, the reducible machine metaphor makes us create factories out of a place that is very far from a machine. It is partly responsible for the declining state of our environment, especially where complex adaptive socio-ecological systems are first reduced to the metaphor of utilitarian "natural resource," and further still to the measure of those preferred "resources" like short-term agronomic production or dollar within a subjectively bounded factory space.

This reduced "field" of the study of various production variables limits the extension of thought to the wider system to landscape ecological function, sociology, climate, river, soil, energy, carbon, or wider consequences. But the statistics within the confines of the study of production can be significant if that be the mark of technocratic success. That significance can create a reflexive validation in the mind of the method, the question, and the mechanical worldview. "Science-led" is no recommendation if the question of "what science and whose science?" is not asked.

The mechanical framing can be the very basis for breaking down vital functional connections because within a synthetic 
connected space such as a landscape, ceteris paribus (all else remains constant) does not hold. In systems theory, you never do just one thing. This practise is connected to this animal and the crop, the animal to the pasture, the pasture to the soil, the soil to fertility, infiltration, root access, erosion, and water-holding capacity, those functions to hydrology, to stream systems, and so on.

The biophysical landscape is itself highly complex. Then add interactions with other interrelated systems; to the landscape's resilience to meteorological events of flood and drought, to cost and return, to market position, to diversity and business risk, to energy demand, to particular dependencies, to productivity (output/input), and to business viability. Consider effects on the well-being of an individual, the household, to the workforce, to their conditions, to local ownership structure, to local community, and to the local service town economics.

\section{Wicked Problems and the Machine}

\begin{abstract}
"If we go through a list of some of the main problematiques that are defining the new Century, such as water, forced migrations, poverty, environmental crises, violence, terrorism, neoimperialism, destruction of social fabric, we must conclude that none of them can be adequately tackled from the sphere of specific individual disciplines. They clearly represent transdisciplinary challenges. This should not represent a problem as long as the formation received by those who go through institutions of higher education, were coherent with the challenge. This is, unfortunately, not the case, since uni-disciplinary education is still widely predominant in all Universities." (Max-Neef, 2005)
\end{abstract}

If we can never do just one thing within complexity, it follows that, if we want to understand and act wisely, we need to be as synthesising as we are analysing. This is the nature of "wicked problems" (Brown et al., 2010): multi-causal, in flux, with multiple connections. Effective analysis requires a synthesising context. Any context-less focus exacerbates the problem, not the reverse. Complex landscapes are not the place for hard-boundary discrete disciplines of knowledge treating each other as immutable billiard balls. Complexity and multiple connections (constantly shifting with context) requires a reimagine from an approach looking to single disciplines communicating across fixed boundaries. Not just to a multidisciplinary approach integrating across academia, but to a transdisciplinary approach inclusive of the field. Transdisciplinary research invites land users to be co-researchers within the knowledge system (Max-Neef, 2005).

\section{COMPLEXITY, EPISTEMOLOGY AND POST-NORMAL SCIENCE: THE UNCERTAIN AND THE UNCONTROLLABLE}

\footnotetext{
"To use the traditional scientific method to deal with issues where facts are uncertain, stakes are high, values in dispute and decisions urgent is to be like the drunkard who lost his keys. Although he had misplaced them elsewhere, he looked for them under the street light because it was the only place where he was able to see. The problem is that the key is not there, we don't even know if there is a key, and
}

the light of the lamppost is getting weaker" [Silvio O. Funtowicz, quoted in Tognetti (1999)].

The ability to synthesise and think into the future is arguably more necessary now than in the past. We live in interesting times, and the future is likely to get even more interesting. There is a nexus of major future issues that will impact seriously on what the future will be - peak oil, energy constraints, population pressures, other resource constraints, including water, reduction in biophysical capacities, including soils, food production and distribution, fundamentalisms of all ilk, and climate change.

Coinciding with that nexus is the emerging ground shift in the philosophy of science as well. The idea that the world can be constructed as a complicated machine is shifting to ideas related to complex systems.

\begin{abstract}
" $[A] n$ increasing interest in complexity [...] has lead to a growing recognition that real world systems can't be completely designed, controlled, understood or predicted as tradition would have it. When organisations do succeed, it's frequently been in spite of, not because of, the way they've been lead, organised and structured. The fact remains that the majority of organisations are still being managed as if they were simple, linear, equilibrium-seeking, and isolated systems, whereas complex research has decidedly demonstrated that thriving organisations are better understood as complex, nonlinear, far-from-equilibrium, and in vital contact with multiple environments." (Goldstein et al., 2004)
\end{abstract}

The factory model of land is being replaced by models that focus on complexity, options, resilience in the face of uncertainty, and building adaptive capacity. However, the mechanical paradigm, with its Newtonian ideal of governing mathematical regularities, persists, like the alchemists and the Ptolemaic astronomers, loyal unto death to an old idea.

As with any complex system, the challenge in shifting from the Modern epistemological construct of Bacon, Descartes, and Newton changes our expectations of predictability and control. Figure 1 is an adaptation of Peterson (Peterson et al., 2003) who challenged our scientific obsession with determinism and reductionism. Most of the world is not like that; certainly not land use systems. Research, policy and practise within the outer realm of complexity and uncontrollability requires different thinking. A similar schema was modified by Funtowicz and Ravetz (1993) and Ravetz (2006) in theorising a post-normal science that - rather than presuming an ideal of universal regularity and prediction - shifts to an ontology that accepts conditions of uncertainty and complexity (post-normal science) where decision stakes are high.

The spaces where the desire of science to be both quantifiable and deterministic are actually compatible with the nature of that space (i.e., significantly knowable by reduction and quantification, such as astrophysics) are where technology finds an easy companionship. These sciences are often called the "hard" sciences: "hard" in the sense that they are readily described quantitatively and with predictability. They occur closer to the convergence of the axes that represent, respectively, increasing complexity (systems that show adaptation and unpredictability) 


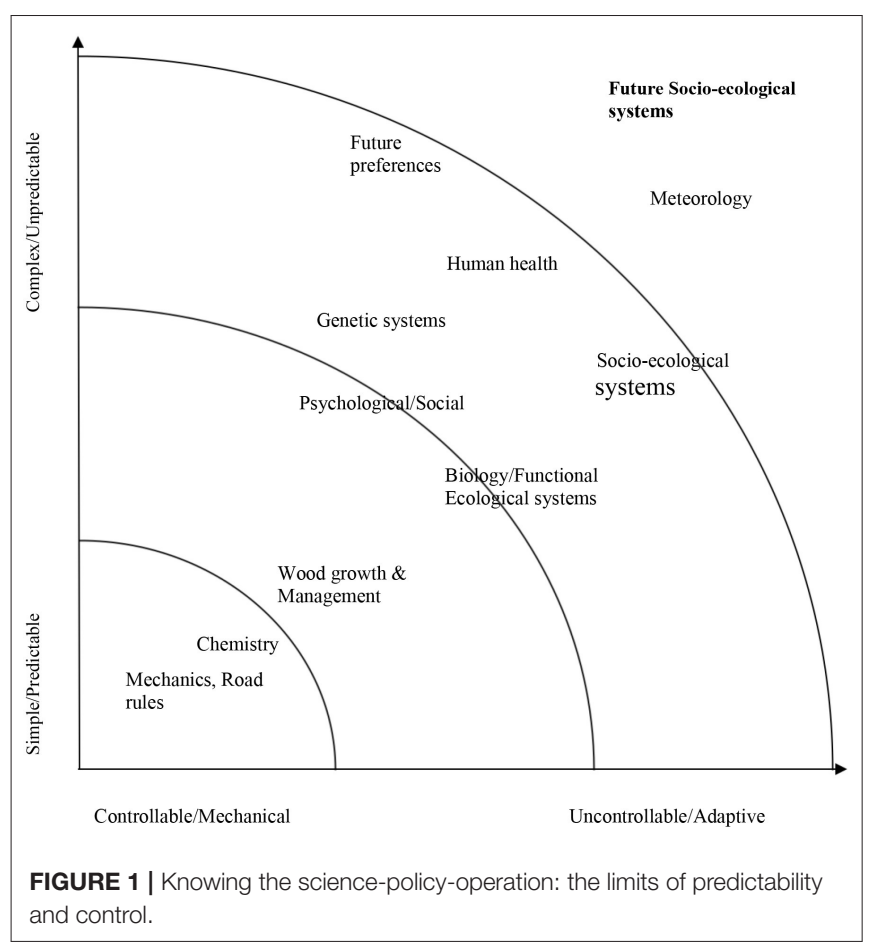

and increasing uncontrollability (systems that are less amenable to human control).

Physics and chemistry are the archetypal hard sciences. Sociology is the archetypal "soft" science. It is "soft" in the sense that it is less amenable to quantification because it includes values that are not integral to an object, and involve aspects that are highly continent and variable. This makes the soft sciences the difficult ones.

For complex landscape and communities, research is better situated in the uncertain and uncontrollable space where there are fewer Newtonian regularities and many more contingent relationships.

\section{From Hard Science to Complex Research}

All sciences have a history, at some point or another, of trying to emulate the hard mechanics of physics and chemistry (even as physics moves beyond a Newtonian world view). An implicit Modern desire to find the elusive universal formulae from which certain and controllable prediction and world building will arise. And from there, the assumption is the wider whole could be built, one brick at a time. Never mind considering the concept of St Paul's as a pre-requisite to its attainment; the myth of the mechanical "System of the World" would provide.

Even some of the Humanities have that history - economics particularly. Ecology had that history, Though it has recently shifted from deterministic views of predictable paths to a "climax" "state of nature" to an appreciation of indeterminism, contingency, and complexity since the 1980's. That was after a longer period of internal dispute, and despite individual scientists arguing against determinism and "climax," such as Ed Ricketts from the 1930's (of Cannery Row fame) and Buzz
Holling from the 1970's, both of whom had observed and witnessed fallsification of the grand theory and argued for that shift to complexity, adaptability, and indeterminism. For those thinkers, being in and of a place provided a wisdom that they ascribed to human intimacy far more than any ideal of dispassionate objectification.

\section{From Agronomic Machines to Ecological Systems}

Ecology is a key science of biological systems of the land, far more significant in breadth and depth of context than agronomy, which remains highly reductive and necessarily narrow of scope. Agronomy suffers from a situation where a certain statistical method drives the research questions (often small and not particularly exploratory) and reflects back on the researcher a convenient presumption of a Newtonian world view. This is problematic because it maintains rather than challenges that Modern worldview (or pretends it is not relevant). In Andrew Sayer's epistemological nexus of Worldview, Question, and Method as a reflexive system of research design, he argued that the considered worldview and the relevance of the question should drive the research method, and not the other way around (Sayer, 1984). Such a principle should particular be applied in the science dealing within a complex multifunctional multiplyconnected space.

In matters of agronomy, the focus on breeding, inputs and yields of usually simplified systems gives statistical results. That is its field, somewhat divorced from the wider connected socioecological environment within which it lives or dies. That is perhaps the biggest mistake that many of the more technical disciplines have made: to presume that the methodologies that suit its substance - the science and technology relating to the physical management of growing a crop - are somehow suited to the far more complex and uncontrollable future and wider spatial world within which people of the land must adapt or fail. That highly subjective position, no matter how much it presumes to be objective and with high verisimilitude, will risk the creation and reinforcement of failures because its worldview may not match the real world or the issue at hand.

The systems multidiscipline, agro-ecology and socio-ecology, provide a context for research that is closer to reality.

\section{REDEFINING SUSTAINABILITY AND THE PATHOLOGY OF RESOURCE MANAGEMENT}

There is an implicit normative framework within all research ("What is it we ought to study?"). With regard to landscapes and communities, that "ought" is influenced by what we think is "sustainability." The definition of "sustainability" is highly dependent on our choice of "ontology" (the concepts, categories and relationships of and between things we unconsciously ignore or observe through our cultural "lens"), again - on the Modern machine or the complex systems worldview. Agricultural and environmental philosopher Thompson $(1997,2007)$ analysed the different worldviews in looking at what "sustainability" means 
to each. He distinguishes between sustainability defined by "Resource Sufficiency" of the mechanical paradigm (the sausage machine of life) and "Functional Integrity" - focused on the maintenance of environmental and social functions, within a system, in an uncertain world. Theories of "resilience" firmly rest in the latter systems worldview (Holling, 1973; Gunderson and Holling, 2002; Walker et al., 2004).

Such a systems world is defined, not by resource "nouns" but by processes, feedbacks and connections, analogous to "verbs" whose actions and participation vary with time, place and other factors. In combination and context, the "functional integrity" that keeps a system within some desired bounds can go awry through either human degradation of economic, environmental and social functions and connections, or through natural perturbation. Loss of "functional integrity" can create "vicious" positive feedback, tipping a socio-ecological system over a threshold to some future unpredictable state.

If we presume that a complex socio-ecological system can be simplified to a mechanical manifestation of the thoughts within a single science discipline, then the loss of key functions we are not aware of is more likely, and, with that, as is the degradation of socio-ecological function. It is thus more likely that a cascade of function loss will occur and a threshold event. Our whole evolutionary history has been dominated by surprise and the capacity or incapacity of any one species to adapt to change. Designing our landscapes as a simple "clone" perfectly "efficient" relative to this current state, in this one place and time, will lead to inevitable extinction. If there is any lesson from evolution, it is that.

The currently predominant industrial land use model emphasises the Economies of Scale of one thing. The rhetoric of "effective farm area" and emphasis on Gross Margin Analysis are consistent with that factory scale model. That emphasis reduces potential Economies of Scope that work with agro-ecological and socio-ecological functions for mutual economic, social and environmental gain. It also increases fragility, input dependency, reduces resilience and increases a potential threshold failure. The emphasis on industrial simplification and mechanical control leads to the increased chance of the system falling out of control. This is what Holling and Meffe (1996) defined as "the pathology of natural resource management": taking complex systems and seeing and then treating them through a Newtonian lens assuming reductionism, determinism, and controllability, resulting in management failure.

\section{DECREASING RESILIENCE BY THE SIMPLIFICATION OF COMPLEX SYSTEMS: THE PADDY}

Living within complex systems necessarily involves surprise, primarily because the integrated landscape and socialscape are complex and connected to multiple environments. Climate, markets, disease, labour issues, price and access to inputs, etc. are all subject to forces of change. Problems arise when we forget that complexity and unpredictability are inherently connected and when we presume that, by simplifying a complex system connected to multiple environments, we somehow magically remove all the unpredictability because it is easier to formulate in a model. It remains a "simple, complex system," but it is still complex.

When you simplify such a complex system, you maintain at least the same level of uncertainty as before but load that inherent uncertainty with a loss of redundancy and the exacerbation of potential cascade effects where one thing leads to another and another. You cannot simplify complexity away. The soils, crops, ecology, weather and climate, markets, and communities are still there. As it is complex, it will surprise, and because it is made simple, it will cascade with one thing leading to another through unpredictable pathways - known and analysable only after the event.

Despite this, we have unknowingly (or perhaps uncaringly) simplified our land-use systems through industrialisation, and the cascades have been evident. The loss of soil function is "solved" by a technological or energy input: more soluble fertiliser and irrigation. The loss of margin in the economies of scale commodity system is "solved" by aggregation, substitution of capital for labour, and migrant labour. The social cascade is "solved" by people shifting away and the biological cascade by more pesticide inputs. The hydrological soil-erosion cascade compensates with fertilisers and irrigation.

Vandana Shiva provided an example of simplified mechanical agronomy applied to a once complex socio-ecological space in her provocatively titled Monocultures of the Mind (Shiva, 1993).

The story she tells of the effect of the Green Revolution on the complex socio-ecological systems of Asian paddy-village life is now a classic within socio-ecological literature. The traditional system involves many different varieties of plants - both rice (up to 14 varieties) and others - to provide resilience against the uncertainties of climate and a better quality of diet. Uncertainty was the ruling paradigm, and reverence, diversity, resilience, and "minimising-the-minimum" was the traditional approach because failure means famine and death. In addition to the paddy rice, koi carp and ducks provide protein and keep insect pests and the mosquito larvae numbers down, so both human health and plant yield are improved. Vegetables from crop rotation, wild plants, and wild animals (including amphibians) supplement the diet. Seeds are saved and replanted. The system is not highly reliant on cash, and much of the system involves functional commons (Ostrom, 1990).

This was a self-organised, low input, and resilient socioecological system; it is not without research needs, but it can be far more readily disrupted if an industrial and narrow agronomic single-disciplinary approach predominates policy, unwittingly reducing the wider ago- ecological and socioecological system resilience.

But this came to pass. Into this complex system, narrow agronomy can significantly increase yields using diploid and haploid mule grains. People are persuaded perhaps because they do not imagine that one new input into the system will impact the resilience of their socio-ecological whole.

Ceteris paribus is the assumption that all else will stay the same, which, when you think of life as a system rather than a 
machine, never happens, especially in a multi-functional socioecological landscape.

Clearing a wetland or a forest does not just create more pasture. Cutting down a tree does not just stop stock from congregating under it. Changing from multiple fertile rice strains to one higher yielding mule strain does not just increase grain supply.

The consequences of any act roll out across multiple and long chains of cause and effect from ultimate cause to proximate cause and to symptom effect. But in Shiva's Green Revolution paddyvillage example, with each new symptom the approach was not to go back and look at the integrity of the wider, deeper paddyvillage (both agro-ecological and socio-ecological) system but to treat each new system effect, the symptom, with another technofix, creating a cascade of symptom to input to symptom and to input again.

The cascades ran through the social and the bio-physical. Farmers have to buy the grain, and cannot save it for next year, so need to develop a line of credit. The grain is indeed a heavy yielder, which means that crop rotations are not sufficient to maintain fertility. The solution for that symptom is to add fertiliser. But the effect of that is that the carp are not as happy, and so we have more mosquitoes. The techno-fix is an insecticide on credit. But that means the ducks are not doing so well anymore, thought the pesticide is dealing with the pests. However, the predator-prey balance is seriously off, so there is a need to buy yet more pesticides on credit because pest numbers have never been so high. Amphibian wild food is also suffering, and the free protein from koi, ducks, and amphibians is therefore depleted. On more credit, people can buy protein.

With all this building credit, the farming focuses on resilience and sufficiency whatever the weather to repay the creditor or risk losing the land. There is thus an increase in the planting of grain for market sale by stopping crop rotations. Because a rest from grain is no longer providing soil improvement or vegetables, the "solution" is to substitute practise for fertiliser input and to buy greens with more credit.

The creditor - usually the largest landowner in the village - forecloses on the debt of those smaller farmers who got into debt once again to buy more seed grain in the hope that next year the grain price will be higher so they can repay the debt. But, unfortunately, just as happened to the US Dustbowl farmers of the 1930's, the high grain production has led to a surplus and a lower price. The consequences include sale, despair, suicide, the exit from the land to swell the poor of the city, there to provide cheap labour.

Eventually, the larger landowner (or bank) is a lot bigger, while the socio-ecological system has collapsed despite GDP being praised; as this is the chosen metric when so many of the system failures are not quantifiable, or are particular to place, governments keep investing in the failure.

\section{The Thoughtscape Derives the Landscape: the Context Changes While the Song Remains the Same}

These are only some of the system effects. There are other potential downstream ecological, resource depletion, psychological, sociological, and political effects. That is why an analytical Newtonian reductionism is questionable without a wider systems context to guide the emphasis of research, policy, and practise. That is how connected are our landscapes. How we think of them - our thoughtscapes - would appear to matter.

The change witnessed above took a previous self-organised, low-input, resilient agro-ecosystem and a socio-ecological system and turned them - through the thoughts and worldview of the advisors - into the factory image they saw in their heads. This is no "objective" research space, made far worse by neither acknowledging that a worldview exists nor considering the wider systems effects, feedback, and thresholds beyond their statistical agronomy.

This paddy example represents an analogy of change for the complex, multi-dimensional, and adaptive socio-ecological landuse systems of many countries, including New Zealand pastoral agriculture. Loss of system function, economic marginalisation, aggregation, and out-of-local displacement of ownership and, with it, the degradation of local economic multipliers, social decline, and the degradation and loss of environmental functions lead to dependency and loss of well-being.

The cascades lead not just to increased fragility, each decade more difficult to escape, but also to a curious stridency of defence of the prevailing Habitus: "This is what we do."

The particular root cause practise will differ and the local context shift, but there is a sociological and psychological cause that lies consistently beneath it all, and that is the industrial lens through which we are taught and teach, and this is reinforced through much research, policies, and commercial messaging.

However, alternatives that emphasise the reality of complex place-based agro-ecological and socio-ecological systems are emerging in increasing strength, not because the ideas being presented by these researchers and practitioners are new (they are not) but because the current industrially- predominant paradigm is increasingly indefensible.

\section{HISTORICAL PATTERNS, CHALLENGES, AND ALTERNATIVES}

Challenging the current industrial-mechanical paradigm requires some understanding of its history, especially with the rise of inputs and economies of scale over the more traditional economies of scope approach that emphasised maintaining a coherent system without the need for expensive inputs. That paradigm shift was never uncontested, and that challenge has become more immediate and far wider in scope with time.

In the 1940's, Sir Alfred Howard contrasted traditional farming systems particularly in Asia with the emerging chemical fertiliser revolution that treated soils more as a physical and chemical hydroponic medium than an biophysical ecosystem (Howard, 1943). America had a number of proponents for treating the land as a system, with better yields, lower inputs, fewer pest control problems, and a better local economy, social, and environmental values. Both Faulkner (1945) and Bromfield (1945) wrote from their personal experience. $\mathrm{N}=1$ case studies can provide exemplars of the extraordinary; opening our eyes 
to what we could have, and be. They also wrote from a perspective where humans are part of the greater system, and touch on philosophy.

The philosophy challenging Modernity paralleled these biophysical exemplars. Leopold (1947) led the way to an integrated world view with A Sand County Almanac, at least in the twentieth century. Carsen (1962) responded to the first real consequence of industrial land use with Silent Spring. The consequences to biodiversity sat alongside a crisis of farm economics. Their challenges were ethical as much as metaphysical.

The cycles of accelerating landscape dysfunction were the focus of Willard Cochrane's technology treadmill metaphor. In 1958, he defined the challenge of continued economic marginalisation resulting from a vicious cycle of increasing production, reducing real prices, reducing cost through scale and yet more land-owner aggregation, technofix industrialism, and social and worker marginalisation (defined in the industrial model as "human resources") ad absurdum (Cochrane, 2003). The process involved different details, but the same general direction of serious family farm crises as Vandana Shiva's paddy example. An absurd process to which asystematic, nonsynthesised analytical thinking is blind.

Few were listening to these commentators on what was happening to the functional health of the wider landscape system in either America, New Zealand, or beyond. The 1970's brought the call to industrialise further. "Get big or get out," and "Plant fencerow to fencerow" was the call of the US Department of Agriculture Secretary Earl Butz. Berry (1977) wrote his classic The Unsettling of America in response, lamenting the industrial effects on communities, families, local economies and the land, and calling it a "crisis of agriculture" derived from a "crisis of culture," of thought, and of worldview.

Agro-ecology emerged in the 1980's as some academics saw the broader issues and the social, environmental, and economic thresholds becoming uncomfortably evident. They were intent on looking at science-based alternatives. Altieri (1983) was followed by researchers looking at the potential to work with rather than against the environment and enhance productivity through within- and between-patch polycultures, and through a far stronger emphasis on the less well-studied soil ecology (perhaps because it is both microscopic in scale and so context-dependent) and soil functional links with animals and grazing management.

Ecological approaches to land use as a challenge to a failing industrial paradigm has only expanded since those early endeavours to solve the problems of industrialism, from Jackson (1980) to work by Jeffrey McNeely and Sara Scherr (McNeely and Scherr, 2003; Scherr and McNeely, 2012). The academic research and literature associated with agro-ecology are now considered. The names proliferate, from regenerative agriculture to eco-agriculture to permaculture, but their essence derives from an agro-ecological rather than an industrial perspective.

Novelists joined in to highlight the moral questions and the loss of values for the benefit of a few, particularly Smiley (1991) and Proulx (2002). Rural Sociology provided an increasing examination of the social and economic consequences to farming families and communities of this policy shift to growing industrial intensification [for example, Bell (2004)].

The New Zealand Parliamentary Commission for the Environment directly challenged the need for a "redesign" of agriculture in 2004 Parliamentary Commission for the Environment (2004). The result was a resounding dismissal from policy makers to the New Zealand farmers' union Federated Farmers.

From the late 2000's, international reports began to emerge, the most significant being UN Special Rapporteur on the Right to Food de Schutter (2011) report to the 2010 General Assembly, which included this statement:

\begin{abstract}
"Based on an extensive review of recent scientific literature, the report demonstratesthat agroecology, if sufficiently supported, can double food production in entire regions within 10 years while mitigating climate change and alleviating rural poverty. The report therefore calls States for a fundamental shift towards agro-ecology as a way for countries to feed themselves while addressing climate and poverty challenges."
\end{abstract}

The evidence de Schutter accumulated, which has been expanded upon in the years since, is clear. The industrial approach to landscapes that treats land as a factory, simplified to suit the mass production of undifferentiated commodity at low cost using high-energy inputs, is unquestionably contributing to significant and planet-threatening environmental problems in the areas of water, soil, biodiversity, and the atmosphere as well as social and economic problems.

The solutions are to see and think about landscapes differently.

\section{SPATIAL AGRO-ECOLOGY: THE POTENTIAL THAT LIES WITHIN MULTI-FUNCTIONAL INTEGRATED AND PATTERNED LANDSCAPES}

Reimagining landscapes as complex adaptive systems is both socio-ecological and agro-ecological. At the core of agroecological thinking is the concept that both biophysical elements (soils, soil ecology, animals, vegetation land covers, water and its function, microclimates, etc.) and land cover patterns can provide mutual and multiple benefits in a designed and managed land system. Those patterns are premised on both the natural variations within a landscape and the connections between and within elements and patches with potential for synergies (landscape mutualism).

Land cover patches include pastures, crops, woodlands, wetlands, tall herbaceous leys, etc. This is a polycultural world with heterogeneity both between and within land cover patches at its core.

The industrial factory view of landscapes works directly against pattern and potential landscape mutualism. It forces the land into a homogeneous uniformity, marching in step whatever the limits and potentials of the terrain. The consequence is dysfunction, an increase in inputs of energy and work in order 
to keep the ideal of the machine far away from anything remotely like a natural patterned and dynamic system.

The classic New Zealand pastoral example involves those farm areas that are dysfunctional in pasture but beneficial in other land covers, historically cleared of functional woodlands and functional wetlands in order to create a never-ending problem pasture. Many of these areas are at the poorer end of pastoral potential, representing $<10 \%$ of the production from the best pastoral areas (Dr. Gordon Cossens, pers. comm. Ken Stephens, pers. Comm.).

That variation in the patterns of production and stock preference is made more complex with the coinciding patterns of real costs. Poor pastoral production is often combined with directly associated threats to the loss of environmental function of value to farm resilience and reliance on inputs: soil degradation, the degradation of both water retention and quality, the degradation of stream systems. Combined with those production and environmental patterns are 80:20 principles of financial costs: stock losses, mustering problems, ineffective returns to fertiliser, high costs in chemical weed control, and repairs and maintenance common to steeper country.

Some attributes - low return, high environmental risk and sensitivity, and high costs - are very often combined. Steep dissected gullies, often the first to revert and avoided by stock, are classic sites. The agricultural emphasis is to clear and put in pasture in the interests of scale (and an unrealistic understanding of the landscape system). Many farmers ignore that "advice" and integrate woodlands into their landscape design. Their real success is neither understood nor embraced by single- discipline pastoralists in research, education, policy, or advice.

\section{The Farm Systems Logic of Spatial Integration of Diverse Land Covers}

Many of these high costs are, for accounting convenience, considered "overheads" - woody weed control, labour, etc. when they are actually direct costs that are difficult (and usually unnecessary) to measure. Costs in these areas are either not counted at all (in the case of soil, water, and biodiversity function) or are assumed to be general - as if the land was a uniform factory rather than a patterned landscape.

The accounting convenience then reflexively morphs back into an unquestioned generalisation in the minds of pastoral analysts. Pastoral agronomists considering whether another land cover, such as woodlands or wetlands, might be better or worse for the whole farm in any particular area fall back into the factory fallacy, the repeated messages from active farm foresters notwithstanding. They consistently make at least five errors, which a socio-ecological and agro-ecological worldview will not.

1. They use average production data rather than actual data from low production areas: so a 2 stock unit/ha (s.u./ha) is presumed to represent the average of $12 \mathrm{s.u}$./ha, and another non-pasture landcover will involve that incorrect loss of revenue.

2. They forget that the category of overhead cost is a convenience and then misrepresent the 80:20 landscape cost patterns for weed control etc., assuming therefore that another non-pasture landcover will involve no cost decrease.
3. There is no consideration given to agro-ecological system effects like animal shelter, shade, any edge browse designs, soil erosion loss, hydrological function, water quality that feeds into stock water and stock health, evapotranspiration reduction etc. A factory does not exhibit system effects because it is not perceived as a system.

4. There is no consideration given to option value from diversity, and the potential emergence of either another source of revenue, cost reduction, ecological function, or input substitution.

5. There is no consideration of the significant social values associated with beauty and living within a highly functional landscape (you can make no apology for the inclusion of this point when you talk with farmers about being on the existential edge and who credit the beauty of their landscape, woodlands, and streams with their return to emotional health).

The general answer from the factory world view is "Don't diversify land covers because you'll lose revenue and you'll have to service the unchanged overheads with that lower revenue." It is false because of the analytical framing and the industrial metaphysics they employ. Just one example of the scope of potential in landscapes not realised because the system is reduced to a simpler worldview.

In direct contrast, agro-ecology designs from within an understanding of the wider system, for multiple gains across economy, society, and environment. It dances with the land and rejoices in the patterns of variation and connection. Agroecological design is effectively a process of creating a "selforganised system" where the system runs without continued energy input, without negative environmental outputs, and with social, resilient, and economic benefits. The soil health, permanently flowing streams, water infiltration and holding, water quality, stock health, resilience, low input, carbon-neutral, community-friendly, profitable, productive, financially efficient, and high -value produce characteristics all go hand in hand.

\section{RESILIENCE TO DROUGHT}

A key landscape system function relates to the threats of drought and flood. One drought crisis occurred between 2008 and 2010 in the rain shadow east coast of New Zealand. The system effects on land, animals, and farming families were considerable though unquantifiable in any general sense. Suicides occurred.

The response was interesting as a sociological study in itself. The approach from most agricultural consultant technocrats was not to look at the land function and capacities as relevant to a solution. The land was fixed: an immutable machine. Drought was simply the absence of rain as an essential (quasihydroponic) input into the mechanism. The solutions were to destock early, wait for rain, and use the occasion to advocate for large-scale irrigation schemes as the technofix solution. Most of the researchers, policy people, and consultants only spoke that language: land as a fixed factory of mechanical parts, inputs, and outputs.

A few of us came in with a question; "What is a drought?" and discussed how the lack of landscape capacity to infiltrate, 
hold, distribute, reduce evapotranspiration, and access deep soil water meant you could have a drought in the afternoon following a $25 \mathrm{~mm}$ rainfall event.

We then started discussing the first principle system capacities within the landscape, relating to soil quality, vegetation, stock management, and landscape water bodies in particular.

The degradation and restoration of landscape systems is well-documented in the eye-witness case study literature and the research. Seeing land as a factory, leading to the reduction of hydrological capacities, impacts not just the lack of resilience to flood and drought but also economic options and community well-being. That cause of degradation is associated, if not directly caused by, seeing land in an input-output mechanical sense, rather than an integrated agro-ecological and socio-ecological system.

The Modern "solutions" are then posited from exactly the same mechanical world view: large centralised dams and irrigation systems. As the shift into systems thinking occurs, it is both the "Third world" countries and those with strong previous and current indigenous practise (and worldview) that are now focusing more on local system hydrological functions (Pearce, 2006; Pretty, 2007; Lancaster, 2013; Nabhan, 2013; Subramanian, 2015).

The local case study by Coller (1959), set in a tributary of the Frazer River in British Columbia, is a case in point. The loss of the landscape systems capacity to hold water, primarily through the loss of beaver dams, led not only to the loss of local scale agricultural irrigation downstream but also to the loss of a fur-hunting livelihood for the local communities. The whole socio-ecological landscape system had been degraded from effectively a sponge with permanently flowing streams and mutualist economic options to a hard plate boom and bust hydrological pattern and mutual losses to the environment, economy, community, and general resilience. The restoration of a keystone landscape function, and with it the retention of the potential energy of water in the landscape, led to multiple positive outcomes because multiple connection and potential mutualism (rather than always assuming Cartesian tradeoffs) is the nature of complex socio-ecological and agro-ecological systems.

\section{MARKET VALUE CHAINS AND AGRICULTURAL STRATEGIES - INDUSTRIAL COMMODITY FAILURES AND ALTERNATIVES}

Reimagining landscapes is strongly associated with the broader primary sector strategies adopted by any country. In broad terms, there are two competing sets of strategies.

1. The Industrial Strategy: the high production of low-cost undifferentiated homogeneous commodities. Landscapes, people, and animals are treated as factory units and inputs with a focus on engineered economies of scale. Primary commodities are sold through short value chains to centralised continuous processing, focusing on economies of scale. This is both the historic colonial model and the agribusiness corporate model.

2. The Diverse Value Strategy: the production of diverse, functionally sustainable, high-quality produce. Landscape, people, and animals are treated as parts of a functioning whole whose functions, patterns, and connections provide the "economies of scope" opportunity for a number of mutual positives, particularly potential cost reduction, revenue option, environmental health, multiple community value chains, and the marketing narrative to retain price position as a price maker, and avoid Cochrane's technology treadmill. Primary production is sold through longer value chains or as direct as possible to end consumers, bypassing middlemen. Processing is more localised and batch processed to maintain a focus on quality and differentiation. This is the emerging strategy geared to suit consumer mega-trends of safe, quality, and sustainable produce with a narrative. The emergence of batchbrewed boutique breweries as an alternative to low-value continuous processed beer is a comparative analogy.

The Industrial Strategy has dominated in New Zealand and much of the once colonial world since the days of European settlement. The energy intensification of land, while retaining a focus on undifferentiated commodities is directly linked with the degradation of rural socio-ecological systems. The explanatory dynamic that lies beneath the degradation of social and environmental function is Cochrane's Technology Treadmill: a repetitive cycle of financial marginalisation and increased industrialism.

The cycle starts with a poor, commodity "price taking" market position, leading to various responses that make the situation worse in the medium and long term. The reality of reduced real agricultural prices that occurred throughout the twentieth Century is connected to this dynamic. The logical response to a lower price is, theoretically, to shift production to an alternative, the negative price-production feedback dance of orthodox economics. However, when there is no alternative because there is no other option, then a commodity lock-in trap occurs. In effect, the focus on commodity "cost efficiency" or gross production of a singular production is the catalyst for the system's demise. Options are lost. The perfect engineered "clone" for these perfect current conditions is more vulnerable to any future change in cost, price, or availability of any supply made critically because of the increasing linearity of the production "line".

The solution within the Industrial Strategy is to continue doing exactly the same "this is what we do" Habitus within colonial and agribusiness commodity land use. Without a production alternative, the first option for a now financially marginal operation within that Habitus is to increase the economies of scale of the operation, retaining the cost-efficiency focus. Farms aggregate, conglomerate, and eventually corporatise with ownership absent and their multiplying expenditure no longer circulating locally. The second is to cut costs further by substituting capital for labour, and migrant labour for local labour, and pushing costs out beyond the horizon to debt, community, or environment. The third is to be swayed 
by new technology as a hopeful saviour - another increase in inputs.

The consequence of each of these steps in improving "cost efficiency" and therefore a temporary margin, is for the stronger buyer of commodities to then decrease prices again. And so within that industrial system, the treadmill continues. Usually, the responses are the same for each iteration of the treadmill. As with drought, the presumption within a Newtonian worldview is that the financial situation is outside their influence. It is what it is: wait - and hope - for rain or a price rise.

This production-market system is another complex adaptive system, very much part of the wider socio-ecological system of the farm and landscape enterprise. Synthesis is what allows policy and research to see the feedbacks, policies, and research needs, not analysis outside any such wider systems context, such as only examining short-term supply and demand production data. This is particularly the case where research looks to ease of quantitative data gathering, or amenability to statistical analysis, rather than what is a more important question however challenging that may be to both the mechanical worldview and preferred method. Some questions are not asked. And the world view and method are not questioned. The lock-in trap of the industrial mindset is as evident within the professions as within real practise in the field.

Cochrane himself, while recognising the treadmill, argued what was effectively another industrial Response: to cap supply (the previous strategy during the Great Depression). However, price is not just a function of supply-demand quantification. Price relates to power differentials between buyer and seller, for example on wage worker on one side of the desk and seven corporate lawyers on the other. Relative supply and demand are but one factor in that power differential. A farmer and a megacorporate buyer are not of equal power whatever the supply and demand situation.

Socio-ecological and agro-ecological systems thinkers propose an alternative. A shift in worldview and Habitus. At root are two things. First, the necessity to focus on price retention and therefore product narrative for the end consumer so that any efficiency gain is retained by the grower and not taken by the buyer. The second is to work with the scope of potential of the agro-ecological and socio-ecological systems, that is, to shift from an industrial factory cost-efficiency "economies of scale" focus to a system resilience "economies of scope" focus. From this, we see the emergence of the Diverse Value Strategy.

\section{WHERE TO GO FROM HERE}

Wendell Berry was right in defining the crisis of agriculture in the 1970's as a crisis of culture. The crisis extends across land use, and has only exacerbated; fewer family farms, poorer communities, threatened environments. The solutions to date have retained the Modern Industrial worldview as their underlying thoughtscape. We have simply moved from colonial commodity industrialism to agribusiness corporate industrialism. This mechanical metaphysic is the water within which we swim without really recognising it or even thinking about it. The factory model still predominates in practise, policy, advice, research, and education as a self-perpetuating Habitus of the status quo. We are taught, we research, we teach, we make policies, we advise, and the next generation continues. This is how we think of the world, and "this is what we do."

For someone educated in science, it is difficult to even listen to the idea that the solutions to our land use and rural community crises are not related to another technology or discovery but to an idea we may have in our heads. It is far more difficult to acknowledge those ideas. It is far more difficult again to think about them. It is more difficult again to change them. We are not taught that we even have them.

A fundamental change to an agro-ecological and socioecological systems view is yet to occur. Agro- ecological thinkers remain marginalised, at least in New Zealand. Modern ideas that dominate land-use minds, ironically considered value-free, are deeply embedded within our culture of land use, perhaps more in the academic, policy, and commerce vocations than the field. It is questionable whether farmers are once again leading the way with the slower inertia of the bureaucracies following.

Notwithstanding the inertia of the industrial mindset, there is such potential in reimagining and redesigning a post-industrial landscape, that its own inertia will inevitably build. The paradigm shifts of the past have often been rapid.

It is neither the logic nor the coherence or the field exemplars that are missing. It may take a single outside event to change: a single reformation moment.

\section{DATA AVAILABILITY STATEMENT}

The original contributions presented in the study are included in the article/supplementary material, further inquiries can be directed to the corresponding author.

\section{AUTHOR CONTRIBUTIONS}

The author confirms being the sole contributor of this work and has approved it for publication.

\section{ACKNOWLEDGMENTS}

None of this work would be possible without colleagues and institutions. Special thanks go to the staff and students of the Centre for Sustainability, Otago University for the motivation, mentoring, and stimulating dialogue. Special thanks to Dr. Hugh Campbell, who understood an epistemological maverick, and shared the heresy. We were all realising that there was a need for change, but the real questions related to the choice of alternatives: thoughts of what strategies, policies, and underlying philosophies could be undertaken and in what direction. The shift in thinking to interconnected systems and away from ever-simpler deterministic machines and colonial commodities was not a hard sell to those minds. Colleagues at Lincoln 
University such as Caroline Saunders, John Reid, and Pablo Gregorini, were important because they shared the same disquiet at the progressive industrialisation of life, meaning, and research. Finally, to the people of the land, especially the farm foresters who were natural systems thinkers, many of whom I have laughed and

\section{REFERENCES}

Altieri, M. (1983). Agroecology: The Scientific Basis of Alternative Agriculture. Berkeley: University of California.

Bell, M. M. (2004). Farming for Us All: Practical Agriculture and the Cultivation of Sustainability. University Park: Pennsylvania State University Press.

Berry, W. (1977). The Unsettling of America: Culture and Agriculture. San Francisco, CA: Sierra Club Books.

Bourdieu, P. (1977). Outline of a Theory of Practice. Cambridge, UK: Cambridge Univ. Press. p. 17. doi: 10.1017/CBO9780511812507

Bromfield, L. (1945). Pleasant Valley. Wooster, OH: Wooster Book Co.

Brown, V. A., Harris, J. A., and Russell, J. Y. (2010). Tackling Wicked Problems: Through the Transdisciplinary Imagination. London: Earthscan.

Carsen, R. (1962). Silent Spring. New York, NY: Houghton Mifflin Co.

Cochrane, W. W. (2003). The Curse of American Agricultural Abundance: A Sustainable Solution. Lincoln; London: University of Nebraska Press.

Coller, E. (1959). Three Against the Wilderness. New York, NY: E. P. Dutton.

de Schutter, O. (2011). Agroecology and the Right to Food. Report to the UN GA 20th December 2010 and the Human Rights Council March 2011. Available online at: http://www.srfood.org/en/report-agroecology-and-theright-to-food (accessed August 5, 2018).

Faulkner, E. H. (1945). Soil Restoration. London: Michael Joseph Ltd.

Funtowicz, S. O., and Ravetz, J. R. (1993). Science for the post-normal age. Futures 25, 735-755. doi: 10.1016/0016-3287(93)90022-L

Gleich, J. (1987). Chaos: Making a New Science. New York, NY: Penguin. p. 14.

Glenna, L. L. (1996). Rationality, habitus, and agricultural landscapes: ethnographic case studies in landscape sociology. Agric. Hum. Values 13, 22-38. doi: 10.1007/BF01530521

Goldstein, J., Allen, P., and Snowdon, D. (2004). Editors' Introduction. Canberra, ACT: Emergence Complexity and Organisation.

Gunderson, L. H., and Holling, C. S. (Eds.). (2002). Panarchy: Understanding Transformations in Systems of Humans and Nature. Washington, DC: Island Press.

Holling, C. S. (1973). Resilience and stability of ecological systems. Annual Rev. Ecol. Syst. 4, 1-23. doi: 10.1146/annurev.es.04.110173.000245

Holling, C. S., and Meffe, G. K. (1996). Command and control and the pathology of natural resource management. Conserv. Biol. 10, 328-337. doi: 10.1046/j.1523-1739.1996.10020328.x

Howard, A. (1943). An Agricultural Testament. Oxford: Oxford Univ. Press.

Jackson, W. (1980). New Roots for Agriculture. Lincoln and London: University of Nebraska Press.

Lancaster, B. (2013). Rainwater Harvesting for Drylands and Beyond, Volume 1: Guiding Principles to Welcome Rain into Your Life and Landscape, 2nd Edn. Tucson, AZ: Rainsource Press.

Leopold, A. (1947), A Sand County Almanac. Oxford: Oxford University Press.

Max-Neef, M. A. (2005). Foundations of transdisciplinarity. Ecol. Econ. 53, 5-16. doi: 10.1016/j.ecolecon.2005.01.014

McNeely, J. A., and Scherr, S. J. (2003). Ecoagriculture: Strategies to Feed the World and Save Biodiversity. Washington, DC: Island Press.

Nabhan, G. P. (2013). Growing Food in a Hotter, Drier Land: Lessons from Desert Farmers on Adapting to Climate Uncertainty. White River Junction, VT: Chelsea Green Publishing.

Ostrom, E. (1990). Governing the Commons: The Evolution of Collective Institutions of Collective Action. Cambridge: Cambridge University Press. doi: 10.1017/CBO9780511807763 argued with and who have taught me so much about land and practise and people: the most complex systems are all connected, contingent, changing, surprising, and beholdent of a strange beauty in a dance if you let yourself see: like a murmuration of starlings at dusk. This is no measured mechanical thing; this life.

Parliamentary Commission for the Environment (2004). Growing for Good: Intensive Farming, Sustainability and New Zealand's Environment. Wellington: Parliamentary Commissioner for the Environment. Available online at: http:// www.pce.parliament.nz/media/pdfs/Growing-for-Good.pdf (accessed August $5,2018)$.

Pearce, F. (2006). When the Rivers Run Dry: Water, The Defining Crisis of the Twenty-first Century. Boston, MA: Beacon Press.

Peterson, G. D., Cumming, G. S., and Carpenter, S. R. (2003). Scenario planning: a tool for conservation in an uncertain world. Conserv. Biol. 17, 358-366. doi: 10.1046/j.1523-1739.2003.01491.x

Pretty, J. (2007). The Earth only Endures. Oxford: Earthscan.

Proulx, A. (2002). That Old Ace in the Hole. New York, NY: Scribner.

Ravetz, J. R. (2006). Post-normal Science and the complexity of transitions towards sustainability. Ecol. Complexity 3, 275-284. doi: 10.1016/j.ecocom.2007. 02.001

Sayer, A. (1984). Method in Social Science: A Realist Approach. London: Routledge. doi: $10.4324 / 9780203310762$

Scherr, S. J., and McNeely, J. A. (2012). Farming With Nature: The Science and Practice of Ecoagriculture. Washington, DC: Island Press.

Scott, J. C. (1999). Seeing Like a State: How Certain Schemes to Improve the Human Condition Have Failed. London: Yale University Press.

Shiva, V. (1993). Monocultures of the Mind: Perspectives on Biodiversity and Biotechnology. London; New York, NY: Zed Books.

Smiley, J. (1991). A Thousand Acres. New York, NY: Anchor Books.

Subramanian, M. (2015). A River Runs Again: India's Natural World in Crisis, from the Barren Cliffs of Rajasthan to the Farmlands of Karnataka. New York, NY: Public Affairs Books.

Thompson, P. B. (1997). Sustainability as a norm. Philos. Technol. 2, 75-94. doi: $10.5840 /$ techne19972230

Thompson, P. B. (2007). Agricultural sustainability: what it is and what it is not. Int. J. Agric. Sustain. 5, 5-16. doi: 10.1080/14735903.2007.9684809

Tognetti, S. S. (1999). Science in a double-bind: Gregory Bateson and the origins of post-normal science. Futures 31, 689-703. doi: 10.1016/S0016-3287(99)0 0027-0

Walker, B., Holling, C. S., Carpenter, S. R., and Kinzig, A. (2004). Adaptability and transformability in social-ecological systems. Ecol. Soc. 9:5. doi: 10.5751/ES-00650-090205

Conflict of Interest: The author declares that the research was conducted in the absence of any commercial or financial relationships that could be construed as a potential conflict of interest.

Publisher's Note: All claims expressed in this article are solely those of the authors and do not necessarily represent those of their affiliated organizations, or those of the publisher, the editors and the reviewers. Any product that may be evaluated in this article, or claim that may be made by its manufacturer, is not guaranteed or endorsed by the publisher.

Copyright (c) 2021 Perley. This is an open-access article distributed under the terms of the Creative Commons Attribution License (CC BY). The use, distribution or reproduction in other forums is permitted, provided the original author(s) and the copyright owner(s) are credited and that the original publication in this journal is cited, in accordance with accepted academic practice. No use, distribution or reproduction is permitted which does not comply with these terms. 